\title{
Comparative Study on Language Features of Disastrous News Items in China and the West-Taking the Crash of Boeing 737 MAX as an Example
}

\author{
Yue Chen $^{1}$ \\ ${ }^{1}$ Department of English, Zhejiang Ocean University, Zhoushan, Zhejiang, China \\ *Corresponding author. Email:zsmalihua@126.com
}

\begin{abstract}
Catastrophic news has always played an important role in news reports, and the frequently crashed Boeing 737 MAX has become a hot spot of disastrous events around the world. This article takes reports from BBC, New York Times and China Daily on the crash of Boeing 737 MAX on March 10, 2019 as examples. The three major functional language theories of Halliday's systemic functional theory can be considered as one of the most influential linguistic theories in the world in recent years, providing us with new perspectives and research methods for discourse analysis. This paper mainly relies on the conceptual function---the function of language to express the relationship between the speaker's internal experience world and the real world, mainly from the aspects of transitivity, rhetoric and the mood structure.It compares the different language styles and characteristics of the media reports of catastrophic news events between China and the West, and has certain reference value for the media in the process of writing disastrous news reports.
\end{abstract}

Keywords: systemic functional linguistics, conceptual function, catastrophic news, Boeing 737

\section{INTRODUCTION}

Disasters have always existed in the daily lives of human beings. Due to its unexpected suddenness, serious harm and destructiveness to people's lives, it often causes widespread and intense social attention. And the media's reports on these disasters are called catastrophic news reports. Since disaster events happen almost every day, no matter they are natural or man-made, news reports about disasters are constantly updated. And they also provides abundant corpus for us to do some discourse research. So research on catastrophic news reports will never be outdated. In this paper, I will analyze the language characteristic of news reports on the crash of Boeing 737 Max in Ethiopia produced by different countries based on Halliday's Systemic Functional Linguistics.

\section{Theoretical Background}

\subsection{Specific Definition of Disastrous News Report}

Disastrous events generally include natural disasters and social disasters. Natural disasters refer to some serious accidents or natural disasters caused by irresistible human forces or non-human factors from nature, such as earthquakes, typhoons, floods, sandstorms, volcanic eruptions and etc. And social disasters refer to major and sudden events caused by human factors or various social contradictions, such as terrorist attacks, wars, air disasters, mine disasters, traffic accidents and other major criminal cases or major liability accidents. So it is not difficult for us to infer that the so-called disastrous news reports are generally refers to reports of the incidents mentioned above. Both the media of China and foreign countries pay a lot of attentions to this kind of news report.

\subsection{Introduction of Systemic Functional Linguistics}

Systemic-Functional Linguistics was created by famous English linguist M.A.K Halliday. In this linguistic theory, Halliday thought that the language has three functions, which are ideational function, interpersonal function and textual function. This paper uses ideational function to analyses the language characteristics of the disastrous newsreport. The ideational function is the function of language which enable human beings to build a mental picture of reality, to make sense of what goes on around them and inside them. It is mainly realized by transitive system. By using Halliday's ideational function theory of language, we can essentially analyze characteristics of the discourse, which help us have a better understanding of the language. 


\section{CORPUS SELECTION AND RESEARCH METHODS}

\subsection{The research purpose and research method}

In order to make a comparison between the catastrophic news reports of China and other countries, this paper chose three news reports, cutting out three articles of the same length as the objects of this study. Taking system function grammar as the basic framework, particular emphasis is put on the transitivity of the reports. When analyzing the difference in the transitivity, this paper lists the specific quantity of two mainly processes used in the report. The specific differences will be presented in tables with textual summaries. And the detailed analysis will be showed below.

\subsection{The Source of the Corpus}

In order to determine texts which can be used to be the object of this study, the author searched online for the news about the crashed Boeing 737 MAX. And then identified selected three articles from China Daily (hereinafter referred to as $\mathrm{CD}$ ), $\mathrm{BBC}$ news(hereinafter referred to as BBC) and The New York Times(hereinafter referred to as NYT). These three articles are titled "Eight Chinese nations on crashed Ethiopian Airlines plane (CD), "Ethiopian Airlines: “ 'NO SURVIVORS' on crashed Boeing 737” (BBC) and "Ethiopian Airlines Plane Is the 2nd Boeing

\section{ANALYSISOFTHELANGUAGESHARACTERISTICSOF CONTENT IN TRANSITIVITY}

The content of the news is the main part of it, which is the continual of the lead words and elaborating the theme announced by the lead words. And in some reports it also answers the question raised in the lead and makes a specific description or expansion of the events that reported in the news. (Huang, Huang, 2015)By comparing the contents of those three news reports, the author finds that the main differences among them mainly exist in the transitivity.

Transitivity is an important part of the conceptual function of the language, used to describe the processes of how people see, hear and act in this world. (Hu, Zhu, 2008: 75) Halliday subdivides the transitivity system into six specific processes: material process, mental process, relational process, behavioral process, verbal process and existential process. This research intercepted a section in similar length of articles respectively and found the processes existed in these reports, and listed the result in Table 1. According to the theme characteristic of the three reports, the research mainly focused on the material process and verbal process. The material process mainly indicates the process for doing some things for specific purpose, and the verbal process generally refers to change information by talking and speaking to other people.

Table 1 Quantitative Statistics of Physical Process and Speech Process

\begin{tabular}{|c|c|c|c|c|c|}
\hline $\begin{array}{l}\text { The } \\
\text { type }\end{array}$ & & process & quantitative & $\begin{array}{c}\text { Total } \\
\text { number }\end{array}$ & proportion \\
\hline \multirow{3}{*}{$\begin{array}{l}\text { Material } \\
\text { process }\end{array}$} & NYT & $\begin{array}{l}\text { crashed, leaving, killing (2), involved, taking off }(2) \text {, } \\
\text { bound for, struggle, ascend, published, sent out, } \\
\text { return to, went down, lost contact, plummeted, rule } \\
\text { out, make, revealed, loaded into, strewn, shuttle, } \\
\text { carrying, include, start, raise, delivered to }\end{array}$ & 30 & 41 & $73 \%$ \\
\hline & $\mathrm{BBC}$ & $\begin{array}{l}\text { Crashed, take off(2), killing, happened, involved, } \\
\text { reported(2), rule out, attribute to, comply with, hit, } \\
\text { burnt down, under way, deliver to, underwent, check, } \\
\text { tweeted, confirmed, held, head to, include, died, wait }\end{array}$ & 24 & 46 & $52 \%$ \\
\hline & $\mathrm{CD}$ & $\begin{array}{l}\text { crash(4), killing(2), use, recovered, shows, died(3), } \\
\text { take off, rushed to, caused to, delivered to, sent out, } \\
\text { given, return, depart, plowing into, sent, extended, } \\
\text { concerned with, grieved for, got into contact with, } \\
\text { confirmed, hope, find out, handle, assist }\end{array}$ & 33 & 61 & $54 \%$ \\
\hline \multirow{3}{*}{$\begin{array}{l}\text { Verbal } \\
\text { process }\end{array}$} & NYT & told, said(4), request & 5 & 41 & $12 \%$ \\
\hline & $\mathrm{BBC}$ & Said(6), told(3), express, & 10 & 46 & $21 \%$ \\
\hline & $\mathrm{CD}$ & $\begin{array}{c}\text { order ,reported(2), asked for, said(7), told, express, } \\
\text { inform, }\end{array}$ & 14 & 61 & $22 \%$ \\
\hline
\end{tabular}

According to Halliday, material process indicates a process of doing, it is mainly described by dynamic verbs and are used to express both concrete and abstract actions while verbal process indicates a processing of saying, which is mainly used to convey some information. (Hu, Zhu, 2008:75,76) In the report from NYT, 30 material processes are mentioned, accounting for $75 \%$ of the total, and most of these verbs or verb phrases are used to describe how the 
plane crashed and what pilots had done before the disaster happened. It was very objective and it also paid more attention the events. And in the reports from $\mathrm{BBC}$ and $\mathrm{CD}$, more abstract verbs were used, for example, BBC used the verb phrase like "rule out, attribute to" to show that it concerned more about the reason of this disaster event. And in CD's report the author found verb phrase like "concerned with, grieved for" to express deep regret for the loss of victims. So $\mathrm{BBC}$ and $\mathrm{CD}$ tends to emphasize the emotions and the attitude of people.

From the table, it is obvious that $\mathrm{CD}$ uses more verbal process. It shows that in addition to focusing on the event, $\mathrm{CD}$ also concerns a lot about the attitudes of people and tries to convey more information. By using verbal process, $C D$ shows us how people in different positions evaluate this accident and what people have done to deal with this tragedy. By quoting the words of different people with different standpoints, the report can help the reader get a more comprehensive understanding of the event. In contrast, the verbal processes used in the report form NYT and BBC are less than that of $\mathrm{CD}$. And most of the verbal processes in The New York Times are given by the officials of government or Boeing Airlines, such as "the national transportation safety board in the United States ". Most of the verbal processes in The BBC News are also provided by the government or Boeing Airlines. We can make a conclusion that NYT and BBC focus more on the social influence of this disaster, and they depend more on the government and Boeing company to ease the tense public relationships.

\section{CONCLUSION}

Disastrous news report is one of the important ways for people to get a more comprehensive knowledge of the disaster events. Due to different writing styles, there exist some differences in different disastrous news report. BBC and The New York Times describe the disaster more objectively and specifically, and also they are more concerned about the reason of this disaster and try to associate several recent accidents. While China Daily pays more attention to the victims and people's attitude toward this event and brings the core idea of people-oriented into full play. Meanwhile the the theory of systematical and functional Linguistics provides us a good way of doing discourse analysis and can help us explore the deeper meaning of the text. And finally this paper did not mention the other two functions of language proposed by Halliday, both of which deserve further discussion.

\section{ACKNOWLEDGMENTS}

The paper was supervised by Miss Ma Lihua with the school of foreign languages, Zhejiang Ocean University, Zhejiang, China

\section{REFERENCES}

[1] Trew,T. What the papers say: linguistic variation and ideological difference .C.//Fowler,R, el. al. Routledge \& Kegan Paul Ltd. Language and Control. London: Routlege \& Kegan Paul,1979:117-156.

[2] Campbell. Framing Environmental Risks and Natural Disasters in Factual Entertainment Television.J. Taylor journal 2014:58-74.

[3]Halliday, M.A.K. An introduction to functional grammar. M.London: Arnold. 2008.

[4] Chen,w,t. (2011) Language Features of English News-Syntax. Technology Information.J.32:234-235

[5] HU,Z,L.,

Zhu,Y,S.,ZHANG,D,1.,LI,Z,Z.(2008)Introduction to Systemic Functional Linguistics.M.Peking University Press,BeiJing.

[6] Zhang,Y,Y.,TU,Q.A Comparative Study of Chinese and Foreign News Media for Reporting International Air Accidents.(2016)Overseas English.J.

[7] Yu,Y,T.,Yang,Y,T.,Zhang,M. A Comparative Study of Chinese and Foreign News Media on Major International News Reports.(2016).J.Chinese market,29 